\title{
Efeito de luz e de imersão em água na germinação de sementes de perpétua produzidas no Estado de São Paulo
}

\author{
ANTONIO SENA FILHO ${ }^{1}$, BENTO MANOEL FERREIRA², VICTOR JULIO FLÓREZ-RONCANCIO \\ e MARIA ESMERALDA SOARES PAYÃO DEMATTÊ ${ }^{4}$
}

\begin{abstract}
RESUMO
Realizaram-se dois experimentos com sementes de perpétua (Gomphrena globosa L.) produzidas em Jaboticabal (SP). No primeiro, em temperaturas alternadas de $20-30^{\circ} \mathrm{C}$, comparou-se apenas o efeito de 16 horas de luz por dia ou de escuro contínuo, para sementes das variedades de inflorescências brancas e purpúreas, logo após sua coleta. Para as duas variedades, verificou-se maior porcentagem de germinação com luz. Nos testes efetuados sem tratamento pré-germinativo e com luz, as médias das porcentagens de germinação variaram entre 64,5 e 81,0\%. Desenvolveu-se o segundo experimento com sementes da variedade de inflorescências brancas, armazenadas durante seis meses em câmara seca. Em temperaturas alternadas de 20-30 ${ }^{\circ} \mathrm{C}$, a germinação foi mais lenta em escuro contínuo do que em 16 horas de luz por dia; a imersão prévia das sementes em água durante 24 horas foi prejudicial tanto à porcentagem como à velocidade de germinação.
\end{abstract}

Palavras-chave: Gomphrena globosa L., sementes, germinação, luz, tratamentos pré-germinativos.

\section{ABSTRACT \\ Effect of light and immersion in water on germination of globe amaranth seeds produced in the State of São Paulo, Brazil}

Two experiments were carried out with seeds of globe amaranth (Gomphrena globosa L.) cultivated at Jaboticabal, SP, Brazil. In the first experiment, at $20-30^{\circ} \mathrm{C}$, the effect of 16 hours light or continuous darkness was compared for seeds of the varieties with white and purple inflorescences, just after their harvest. For both varieties, a higher germination percentage was verified under light. Without pretreatments for germination and under light, the average germination percentage ranged from 64.5 to $81.0 \%$. The second experiment tested seeds of the variety with white inflorescences, stored for six months in a dry chamber. Germination at alternate temperatures of $20-30^{\circ} \mathrm{C}$ was slower in continuous darkness than in photoperiod of 16 hours; the previous immersion of the seeds in water for 24 hours was harmful to the germination percentage and to the germination speed.

Key words: Gomphrena globosa L., seeds, germination, light, pretreatments for germination.

\footnotetext{
${ }^{1}$ Secretaria de Agricultura e Abastecimento, Casa da Agricultura, Avenida 13 de Maio, 946, 14870-000 Jaboticabal (SP).

${ }^{2}$ Sementes Polato, Rua Dom Pedro II, 332, 78700-220 Rondonópolis (MT).

${ }^{3}$ Universidad Nacional de Colombia, Facultad de Agronomía, Santafé de Bogotá, D.C., Colombia.

${ }^{4}$ Departamento de Produção Vegetal, Faculdade de Ciências Agrárias e Veterinárias da Universidade Estadual Paulista, Via de Acesso Prof. Paulo Donato Castellane, s/n, 14884-900 Jaboticabal (SP). Bolsista do CNPq. Autora para correspondência.
} 


\section{INTRODUÇÃO}

Gomphrena globosa L., Amaranthaceae, é uma planta herbácea anual originária da Índia (CORRÊA \& PENNA, 1978; LORENZI \& SOUZA, 2001). Produz inflorescências pequenas, globosas, ornamentais, que, depois de secas, permanecem com a aparência inalterada por longo tempo; daí seu nome popular de "perpétua". Suas inflorescências podem ser vermelhas, branco-creme, violáceas ou alaranjadas; essa diversidade ocorre por cruzamento natural (CORRÊA \& PENNA, 1978). É apropriada para compor canteiros em jardins, ou para produção de flores de corte, frescas ou secas. Tem propriedades medicinais e fornece matéria corante violeta, para alimentos (CORRÊA \& PENNA, 1978). É muito usada como indicadora de viroses (VALLEJO et al., 1994). Tem sido classificada como espécie invasora (BRASIL, 1992), mas esse conceito, em condições brasileiras, aplica-se melhor às espécies silvestres Gomphrena brasiliana L. [=Alternanthera brasiliana (L.) O. Kuntze], Gomphrena ficoidea L. [Alternanthera ficoidea (L.) R. Br.] e Gomphrena celosioides Mart. (LORENZI, 1982).

A produção de sementes de plantas ornamentais, no Brasil, ainda é uma atividade incipiente. Especialmente no tocante a flores anuais, as sementes utilizadas para produção são importadas e, muitas vezes, híbridas.

De acordo com LORENZI \& SOUZA (2001), G. globosa é cultivada a pleno sol e propaga-se facilmente por sementes, produzidas em grande quantidade, que podem ser semeadas em qualquer época do ano, principalmente durante o verão. Essas afirmações levam a crer que a produção de sementes dessa espécie pode ser bem sucedida em nosso meio, mas não foram encontradas informações na literatura sobre o desempenho germinativo de sementes de perpétua produzidas no Brasil.

Este é um estudo preliminar que teve o objetivo de testar a germinação de sementes de G. globosa coletadas de plantas cultivadas a pleno sol, em Jaboticabal (SP), avaliando-se o efeito de luz e de imersão prévia das sementes em água.

\section{MATERIAL E MÉTODOS}

Alguns procedimentos adotados basearam-se nas especificações para Gomphrena globosa encontradas nas Regras para Análise de Sementes (BRASIL, 1992): temperatura para os testes, substrato e datas de contagem.

\section{1. Primeiro experimento}

Com sementes de duas variedades de G. globosa, caracterizadas por inflorescências brancas e purpúreas, logo após sua colheita, em março de 1991, desenvolveu-se um teste comparando duas condições: fotoperíodo de 16 horas e escuro contínuo.

Realizou-se experimento em germinador vertical com temperaturas alternadas de $20-30^{\circ} \mathrm{C}$. Utilizaram-se como substrato três folhas de papel-filtro colocadas no fundo de caixas "gerbox" transparentes para os tratamentos com luz e pretas para aqueles no escuro. Esse substrato foi umedecido com solução de Nistatin a $0,1 \%$, para evitar ataque de fungos. Considerou-se como unidade experimental uma caixa contendo 50 sementes. Os tratamentos, em delineamento inteiramente casualizado, foram repetidos quatro vezes, realizando-se a análise em esquema fatorial.

Efetuaram-se as contagens de sementes germinadas diariamente, entre 7 e 14 dias após a instalação do experimento. Nos tratamentos mantidos no escuro, fizeram-se as contagens sob luz verde, para evitar a influência da luz comum. Com os dados obtidos, calcularam-se porcentagem e índice de velocidade de germinação (IVG), este último de acordo com a fórmula de MAGUIRE (1962):

$$
\mathrm{IVG}=\frac{\mathrm{N} 1}{\mathrm{D} 1}+\frac{\mathrm{N} 2}{\mathrm{D} 2}+\cdots \frac{\mathrm{Nn}}{\mathrm{Dn}}, \text { sendo: }
$$

$\mathrm{N} 1$ = número de sementes germinadas no primeiro dia de contagem;

$\mathrm{N} 2$ = número de sementes germinadas entre o primeiro e o segundo dia de contagem;

$\mathrm{Nn}=$ número de sementes germinadas entre o penúltimo e o último dia de contagem;

D1 = número de dias entre a instalação do teste e a primeira contagem;

D2 = número de dias entre a instalação do teste e a segunda contagem;

$\mathrm{Dn}=$ número de dias entre a instalação do teste e a última contagem. 


\subsection{Segundo experimento}

Os procedimentos gerais foram idênticos aos do primeiro.

Sementes de plantas de inflorescências brancas, coletadas em outubro de 1990 e armazenadas durante seis meses em câmara seca (a, aproximadamente, $21^{\circ} \mathrm{C}$ e $40 \%$ de umidade relativa do ar), foram submetidas a um teste de germinação com os seguintes tratamentos: fotoperíodo de 16 horas; fotoperíodo de 16 horas com imersão prévia das sementes em água durante 24 horas; escuro contínuo; escuro contínuo com imersão prévia das sementes em água durante 24 horas.

\section{RESULTADOS E DISCUSSÃO}

Nas Regras para Análise de Sementes (BRASIL, 1992), encontra-se a informação de que o fornecimento de luz por 8 a 16 horas pode ser benéfico à germinação de G. globosa. Os resultados do presente estudo confirmam essa indicação.

No primeiro experimento (Tabela 1), para as duas variedades, verificou-se menor porcentagem de germinação em escuro contínuo.

No segundo experimento (Tabela 2), as sementes, em escuro contínuo, germinaram mais lentamente; a imersão prévia das sementes em água foi prejudicial tanto à porcentagem como à velocidade de germinação.

Comparando os resultados obtidos para a variedade de inflorescências brancas em ambos os experimentos, verifica-se que os valores de porcentagem de germinação e de IVG são próximos nos tratamentos respectivos. Isso pode indicar que o armazenamento durante seis meses não prejudica o comportamento germinativo das sementes.

\section{CONCLUSÕES}

1. Sementes de Gomphrena globosa L. de inflorescências brancas e purpúreas, produzidas em Jaboticabal, germinaram bem em temperaturas alternadas de $20-30^{\circ} \mathrm{C}$, sem tratamento pré-germinativo.

2. Para sementes das duas variedades, o fotoperíodo de 16 horas proporcionou melhor germinação do que o escuro contínuo.

3. Para o lote de sementes da variedade de inflorescências brancas armazenado durante seis meses, a pré-imersão em água foi prejudicial à germinação.

Tabela 1. Germinação de sementes recém-colhidas de duas variedades de Gomphrena globosa L. expostas ou não à luz

\begin{tabular}{lcc}
\hline \multicolumn{1}{c}{ Tratamentos } & Germinação & IVG $^{2}$ \\
\hline & $\%$ & \\
Variedade branca; 16 horas de luz & 81,0 & 5,50 \\
Variedade branca; escuro contínuo & 6,0 & 6,65 \\
Variedade purpúrea; 16 horas de luz & 6,52 \\
Variedade purpúrea; escuro contínuo & 62,5 & 5,70 \\
Médias da variedade branca & $70,00 \mathrm{a}$ & $5,07 \mathrm{a}$ \\
Médias da variedade purpúrea & $63,50 \mathrm{a}$ & $5,96 \mathrm{a}$ \\
Médias dos tratamentos com luz & $72,75 \mathrm{a}$ \\
Médias dos tratamentos em escuro contínuo & $60,75 \mathrm{~b}$ \\
F & & $5,86 \mathrm{a}$ \\
Fator A (variedade) & $5,17 \mathrm{a}$ \\
Fator B (16 horas de luz ou escuro contínuo) & $1,60 \mathrm{~ns}$ \\
A x B & $4,84 *$ \\
Coeficiente de variação (\%) & $3,66 \mathrm{~ns}$ \\
\hline
\end{tabular}

${ }^{1}$ As médias aqui apresentadas foram calculadas com os dados originais; a análise estatística foi feita com dados transformados. Médias seguidas por letras diferentes variam pelo teste $\mathrm{F}$ a $5 \%$.

2 Índice de velocidade de germinação, segundo MAGUIRE (1962).

ns = não significativo $; *$ significativo a $5 \%$ de probabilidade pelo teste $\mathrm{F}$. 
Tabela 2. Germinação de sementes de Gomphrena globosa L. de inflorescências brancas em diferentes tratamentos, após seis meses de armazenamento

\begin{tabular}{lc}
\hline \multicolumn{1}{c}{ Tratamentos } & Germinação \\
\hline & $\%$ \\
16 horas de luz & 80,50 \\
16 horas de luz; imersão em água & 57,50 \\
Escuro contínuo & 73,50 \\
Escuro contínuo; imersão em água & 52,00 \\
Médias dos tratamentos com luz & $69,00 \mathrm{a}$ \\
Médias dos tratamentos em escuro contínuo & $62,75 \mathrm{a}$ \\
Médias dos tratamentos sem imersão em água & $77,00 \mathrm{a}$ \\
Médias dos tratamentos com imersão em água & $54,75 \mathrm{~b}$ \\
F & \\
Fator A (16 horas de luz ou escuro contínuo) & $0,84,67$ \\
Fator B (sem e com imersão em água) & $12,31 * *$ \\
A B & $0,01 \mathrm{~ns}$ \\
Coeficiente de variação (\%) & 14,71 \\
\hline
\end{tabular}

${ }^{1}$ As médias aqui apresentadas foram calculadas com os dados originais; a análise estatística foi feita com dados transformados. Médias dos tratamentos com luz e em escuro contínuo seguidas por letras diferentes variam entre si pelo teste $\mathrm{F}$ a 5\%; médias dos tratamentos sem e com imersão em água seguidas por letras desiguais diferem entre si pelo teste F a 1\% (porcentagem de germinação) e 5\% (IVG).

2 Índice de velocidade de germinação, segundo MAGUIRE (1962).

ns $=$ não significativo ${ }^{*}, * *=$ significativo, respectivamente, a 5 e a $1 \%$ de probabilidade pelo teste $\mathrm{F}$.

\section{REFERÊNCIAS BIBLIOGRÁFICAS}

BRASIL, Ministério da Agricultura e Reforma Agrária. Regras para análise de sementes. Brasília: Ministério da Agricultura e Reforma Agrária, 1992. p.120-321.

CORREAA, M.P. \& PENNA, L. de Dicionário das plantas úteis do Brasil e das exóticas cultivadas. Rio de Janeiro: Ministério da Agricultura, Instituto Brasileiro de Desenvolvimento Florestal, 1978. v.5, p.461.

LORENZI, H. Plantas daninhas do Brasil: terrestres, aquáticas, parasitas, tóxicas e medicinais. Nova Odessa: Editora Plantarum, 1982. p.4-14.
LORENZI, H. \& SOUZA, H.M. de. Plantas ornamentais no Brasil: arbustivas, herbáceas e trepadeiras. 3.ed. Nova Odessa: Editora Plantarum, 2001. p.135.

MAGUIRE, J.D. Speed of germination - aid in selection and evaluation for seedling emergence and vigor. Crop Science, Madison, v.2, n.2, p.176-177, 1962.

VALLEJO, R.L.; COLLINS, W.W.; SCIAVONE, R.D.; LOMMEL, S.A. \& YOUNG, J.B. Extreme resistance to infection by potato virus $\mathrm{Y}$ and potato virus $\mathrm{X}$ in an advanced hybrid Solanum phureja - S. stenotomum diploid population. American Potato Journal, Orono, v.71, n.10, p.617-628, 1994. 